\title{
New Results on Gain-Loss Asymmetry for Stock Markets Time Series
}

\author{
M. Grudziecki ${ }^{a}$, E. Gnatowska ${ }^{a}, \mathrm{~K} \mathrm{Karpio}^{b}$, \\ A. OrŁowski ${ }^{b, c}$ AND M. ZaŁuskA-KotuR ${ }^{a, c}$ \\ ${ }^{a}$ Faculty of Mathematics and Natural Sciences \\ Card. Stefan Wyszyński University, Dewajtis 5, 01-815 Warsaw, Poland \\ ${ }^{b}$ Department of Informatics, Warsaw University of Life Sciences - SGGW \\ Nowoursynowska 166, 02-787 Warsaw, Poland \\ ${ }^{c}$ Institute of Physics, Polish Academy of Sciences \\ al. Lotników 32/46, 02-668 Warsaw, Poland

\begin{abstract}
A method called investment horizon approach was successfully used to analyze stock markets of many different countries. Here we apply a version of this method to study characteristics of the Polish Pioneer mutual funds. We decided to analyze Pioneer because of its longest involvement in investing on the Polish market. Moreover, it apparently manages the biggest amount of money among all similar institutions in Poland. We compare various types of Pioneer mutual funds, characterized by different financial instruments they invest in. Previously, investment horizon approach produced different characteristics of emerging markets as opposed to mature ones, providing a possible way to quantify stock market maturity. Here we generalize the above mentioned results for mutual funds of various types.
\end{abstract}

PACS numbers: 89.65.Gh, 02.50.-r, 89.90.+n

\section{Introduction}

Tools, methods, and approaches that have been worked out to describe physical phenomena are recently more and more often used in the analysis of economical data [1-3]. In this paper we study data from the Polish market by using one of such methods called investment horizon approach [4-11]. Usual analysis of economic data relies on the distribution of returns corresponding to a fixed time window. Investment horizon approach is an adaptation of a different method based on inverse statistics concept. Instead of a distribution of returns for a given time window, we analyze here a distribution of time periods, that one has to wait until assumed return value is achieved. This waiting time is our investment horizon at a given (assumed) return level. It has been shown that such a distribution may be described by a universal curve [4-7]. The time for which the maximum of this distribution is found is called optimal investment time and it increases as a power 
of the return level. For all analyzed data the exponent of the power dependence on the return value of the signal is different for positive returns (describing gains) than it is for negative ones (describing losses) [4-11]. We have shown recently $[9,10]$ that the parameter $\kappa$ defined as a difference of gain and loss slope parameters is greater than zero for mature and less than zero for emerging markets, when stock indices are analyzed. Below we continue our study of the parameter $\kappa$ for mutual funds in Poland, in particular we focus our attention on Pioneer Investment Group. It appears that in this case it is not the sign of $\kappa$ that differentiate between various fund types. The more aggressive funds are characterized by larger values of parameter $\kappa$, whereas those of limited risk have $\kappa$ values closer to zero.

\section{Procedure and results}

Method used herein is called analysis of investment horizons and is based on an idea of inverse statistics. Traditionally a distribution of return rates is calculated for a fixed period of time. Such distributions provide information of what is the probability that an investment will give gain or loss after the assumed time period. In the inverse statistics approach we analyze time periods (investment horizons) that an investor has to wait in order to obtain assumed gain (or loss). Calculated time depends, of course, on the point in time when the investment has been done. For all the possible investment times we obtain a distribution of investment horizons. The position of its maximum denotes an optimal investment time horizon. We can easily obtain the maximum after fitting the data to the formula below

$$
p(t)=a \frac{\exp \left(\frac{-a^{2}}{t+b}\right)}{\sqrt{\pi}(t+b)^{3 / 2}}, \quad t_{\max }=\frac{2}{3} a-b,
$$

where $a, b$ - fitted parameters, $t_{\max }$ - maximum of the distribution. Then we compare investment horizons as a function of return rate for positive and negative return rates. A difference of slope parameters for gain and loss is defined as an asymmetry parameter for studied mutual funds. More details on this procedure can be found in [5].

In analysis we use $\ln (s(t))$, where $s$ denotes price at a day $t$, as our time series. We start with a subtraction of a short-term trend assumed as 100-day moving average. Figure 1 shows the logarithm of price time series together with a trend for one of the analyzed mutual funds. All the remaining pictures are prepared for the same mutual fund.

Next, we calculate distributions of investment horizons for various return rates $(\rho)$ assumed. One of those distributions, for return rate equal to 0.04 , together with fitted function is presented in Fig. 2. The optimal (most probable) investment time is in this case equal to 8 days.

We can also compare a dependence of optimal investment times for the return rates of the same absolute values (Fig. 3). For the considered mutual fund the loss comes before gain. The points for gain are above those for loss. After calculating 


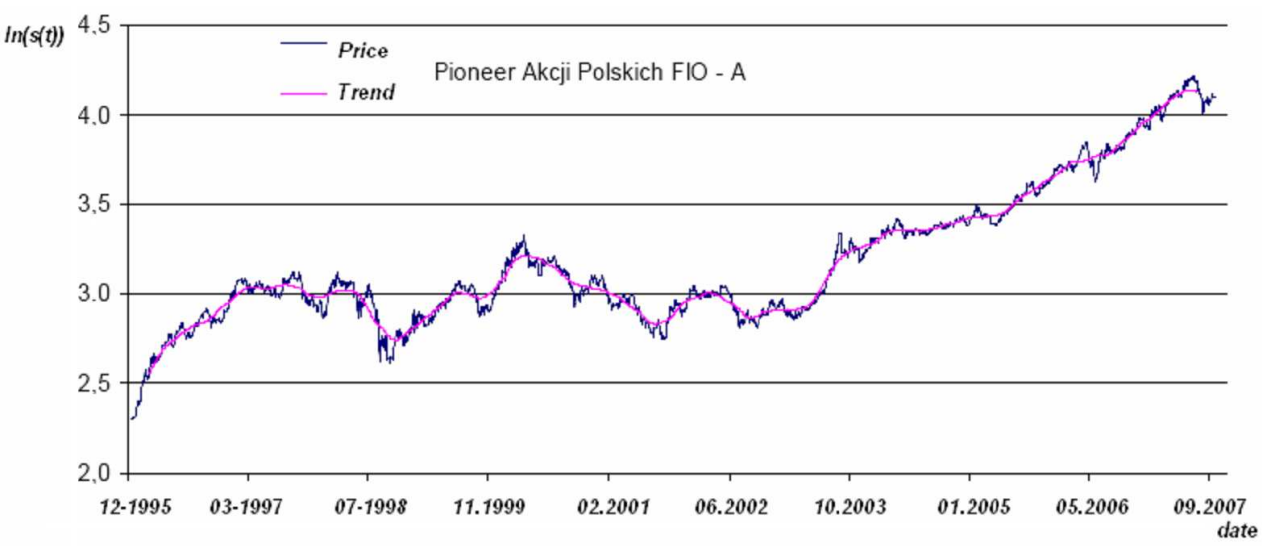

Fig. 1. Logarithms of price time series for one mutual fund together with its trend.

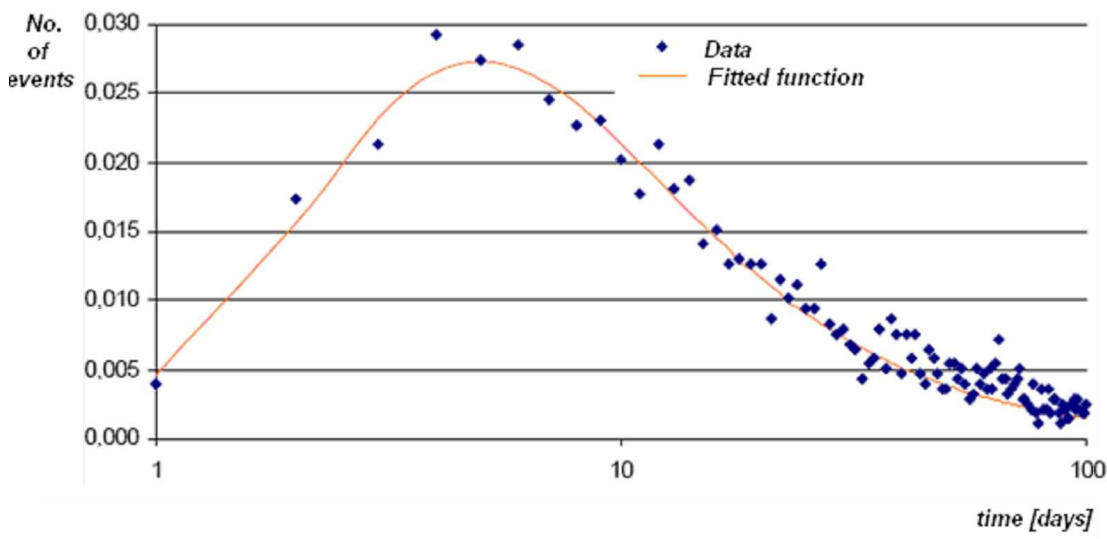

Fig. 2. Distribution of investment horizons (with fitted function) for return rate 0.04.

the slope parameters in $\log -\log$ scale we can obtain asymmetry coefficient. They happen to be positive in this case. The same result has been previously obtained for mature stock markets, like NYSE.

Our final results are summarized in Table. We can divide analyzed mutual funds into three groups, according to their scope of investment. For comparison, also data for some of Polish stock market indices are presented.

To check the statistical significance of the results, the so-called determination coefficient $R^{2}$ has been calculated. About $99 \%$ of volatility in data is described (explained) by the fitted function. For Pioneer Akcji Polskich FIO we get 99.23\% (gain) and 98.83\% (loss). For Pioneer Akcji Amerykańskich FIO we have 99.23\% (gain) and $99.37 \%$ (loss).

Asymmetry coefficient may give information about stock market maturity. In the case of mutual funds investing into stock market it might tell about preferred 


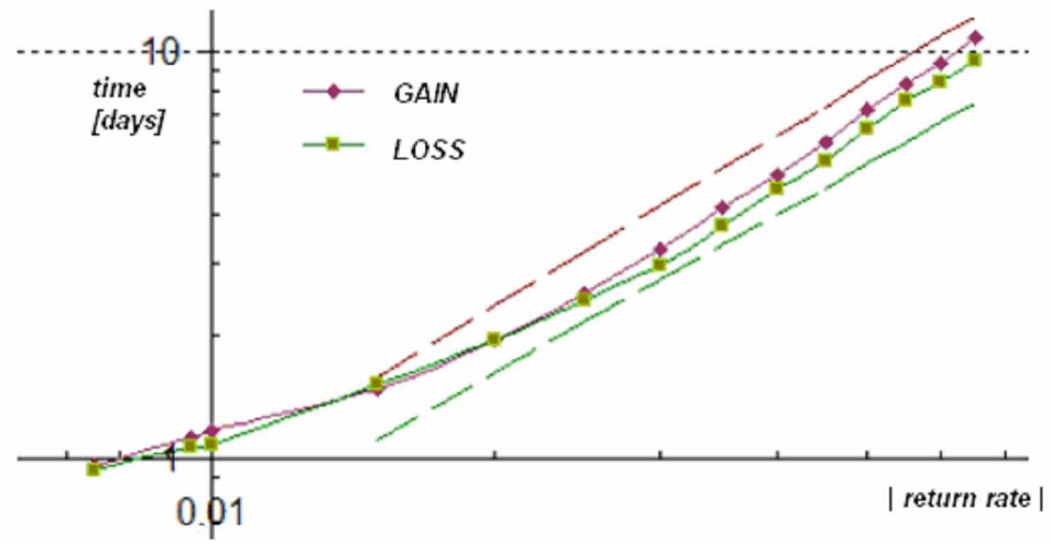

Fig. 3. Investment horizon as a function of absolute value of a return rate.

TABLE

Values of slope parameters and asymmetry coefficient for analyzed mutual funds. For convenience there are also data for WIG and WIG20 - main Polish stock market indices.

\begin{tabular}{|c|c|c|c|}
\hline \multirow[t]{2}{*}{ Name } & \multicolumn{2}{|c|}{ Slope parameter } & \multirow[t]{2}{*}{ 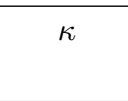 } \\
\hline & $\rho>0$ & $\rho<0$ & \\
\hline \multicolumn{4}{|l|}{ 1. Stocks-based funds } \\
\hline Pioneer Akcji Amerykańskich FIO - A (USD) & 1.5496 & 1.3347 & 0.2149 \\
\hline Pioneer Akcji Europejskich FIO — A (EUR) & 1.6003 & 1.3188 & 0.2815 \\
\hline Pioneer Akcji Polskich FIO - A & 1.3967 & 1.3011 & 0.0956 \\
\hline WIG & 1.1980 & 1.2464 & -0.0484 \\
\hline \multicolumn{4}{|l|}{ 2. Stable growth funds } \\
\hline Pioneer Stabilnego Wzrostu FIO - A & 1.2019 & 1.2243 & -0.0224 \\
\hline Pioneer Zrównoważony FIO — A & 1.4568 & 1.4843 & -0.0275 \\
\hline SFIO T.P. & 1.1791 & 1.2931 & 0.0243 \\
\hline WIG20 & 1.3888 & 1.3434 & 0.0454 \\
\hline \multicolumn{4}{|l|}{ 3. Obligation funds } \\
\hline Pioneer Obligacji FIO - A & 1.2779 & 1.2809 & -0.003 \\
\hline Pioneer Obligacji Dolarowych FIO — A (USD) & 1.1236 & 1.0958 & 0.0278 \\
\hline Pioneer Obligacji Dolarowych Plus FIO — A (USD) & 1.2612 & 1.1891 & 0.0721 \\
\hline Pioneer Obligacji Europejskich Plus FIO — I (EUR) & 1.1431 & 1.1723 & -0.0292 \\
\hline
\end{tabular}

investment strategies (or management politics). Based on the obtained results one can conclude that if we invest money for a short time, we will get loss, regardless of the mutual fund. 
This behavior is just opposite to WIG index, where gain comes first. Similar short-term investment on mutual funds from a second group could give gain or loss more evenly. All the mutual funds from this group are characterized by values of asymmetry coefficient close to zero. These could be determined by the limited risk of the investment. Such mutual funds invest part of the money into safe government bonds. Similarly do mutual funds from the last group. Those institutions by investing in government bond are obviously the safest. This time we get small absolute values of the coefficient again. This property can be related to the level of risk accompanying an investment.

When standard return rates distributions are analyzed, the skewness parameter (i.e., third standardized moment) measures their asymmetry properties. The question is whether this kind of asymmetry is anyhow related to the parameter $\kappa$ studied in this paper. The (unobvious) answer seems to be "no". We calculated values of skewness for all data presented here. In the first, top part of our table, calculated values of skewness are as follows: $-0.22,-0.55,-0.36$, and 0.032 (for WIG). We see that although signs of both parameters are consequently opposite, their values do not correlate with each other. For the next two parts of the table, skewness changes from -0.45 to 0.35 , and there is still no correlation at all (this time not only for the values but also for the signs of the parameter $\kappa$ ).

\section{Conclusions}

Because of a huge number of financial products available one shall not rely only on the return rates as a market characteristic. Instead there is a need for a more detailed comparison of offered investment possibilities and their consequences. The investment horizon approach gives us a tool to evaluate and compare a level of an investment risk. The smaller absolute value of $\kappa$ is, the smaller is also the risk. However, comparing even similar mutual funds one shall keep in mind that they can operate on the different markets. The funds from our third group are a good example. Two of them operate on the US market, investing in American government bonds. Such market is much more mature than the Polish market, thus the obtained results should not necessarily be considered a surprise.

\section{References}

[1] R.N. Mantegna, H.E. Stanley, An Introduction to Econophysics: Correlations and Complexity in Finance, CUP, Cambridge, England 2000.

[2] N.F. Johnson, P. Jefferies, P.M. Hui, Financial Market Complexity, Oxford University Press, Oxford 2003.

[3] J.P. Bouchaud, M. Potters, Theory of Financial Risks: from Statistical Physics to Risk Management, Cambridge University Press, Cambridge 2000.

[4] M.H. Jensen, A. Johansen, F. Petroni, I. Simonsen, Physica A 340, 678 (2004).

[5] M.H. Jensen, A. Johansen, I. Simonsen, Int. J. Mod. Phys. B 17, 4003 (2003).

[6] M.H. Jensen, A. Johansen, F. Petroni, I. Simonsen, Physica A 324, 338 (2003). 
[7] I. Simonsen, M.H. Jensen, A. Johansen, Eur. Phys. J. B 27, 583 (2002).

[8] M.H. Jensen, A. Johansen, I. Simonsen, F. Petroni, Physica A 340, 678 (2004).

[9] M.A. Załuska-Kotur, K. Karpio, A. Orłowski, Acta Phys. Pol. B 37, 3187 (2006).

[10] K. Karpio, M. Załuska-Kotur, A. Orłowski, Physica A 375, 599 (2007).

[11] P.T.H. Ahlgren, M.H. Jensen, I. Simonsen, R. Donangelo, K. Sneppen, Physica A 383, 1 (2007). 